\title{
O OLHAR DOCENTE SOBRE A DANÇA
}

\author{
Sandy Silveira ${ }^{1}$ \\ sandysilvleira592@gmail.com \\ Caroline Carvalho² \\ ccarvalho.caroline@gmail.com
}

\section{RESUMO}

O presente estudo exploratório efetiva-se por meio de uma pesquisa qualitativa, que oportuniza análises de dados coletados atrávez de entrevistas realizadas com três professoras educacionais infantis de uma rede de ensino privada localizada na cidade de Gaspar - SC. Tendo como enfoque, oportunizar possíveis costuras de dialogos entre teorias e práticas educacionais e suas relações com o movimento corporal na infância. Contudo, o presente estudo propõe a utilização da comunicação não verbal - linguagem corporal - como ferramenta facilitadora do processo de aprendizagem das crianças pequenas, oferecendo e defendendo a dança como utensilio metodológico agregador, sendo compreendida como uma grande aliada no que diz respeito a preocupação com o desenvolvimento da criança.

Palavras-chave: Infância. Dança. Aprendizagem. Educação infantil.

\section{ABSTRACT}

This exploratory study is carried out through a qualitative research, which provides opportunities for analysis of data collected through interviews conducted with three children's educational teachers from a private education network located in the city of Gaspar - SC. Focusing on creating opportunities for possible dialogues between theories and educational practices and their relationship with body movement in childhood. However, this study proposes the use of non-verbal communication - body language - as a tool to facilitate the learning process of young children, offering and defending dance as an aggregating methodological tool, being understood as a great ally with regard to the concern with the child's development.

Key words: Childhood. Dance. Learning. Child education.

\footnotetext{
${ }^{1}$ Graduanda em dança pela Universidade Regional de Blumenau, cursando a sétima fase do curso.

2 Doutoranda em Educação pela UFPR. Mestre em Educação pela UNIVALI. Graduada em Bacharelado e Licenciatura em Teatro pela FURB. Professora e Coordenadora do Curso de Licenciatura em Teatro da FURB. Pesquisadora do grupo de Pesquisa Arte e Estética na Educação do Programa de Mestrado e Doutorado em Educação da FURB. Integrante da Linha de Pesquisa Linguagem, Corpo e Estética e do Grupo de Pesquisa LABELITE do Programa de Mestrado e Doutorado em Educação da UFPR. Escritora de literatura para a infância com quatro títulos publicados e duas premiações.
} 


\section{INTRODUÇÃO}

Esta pesquisa trata-se de um estudo exploratório que tem como objetivo proporcionar familiaridade com um problema, com vista a torná-lo mais explícito, conforme aponta Gil (2002, p. 41). Portanto, este estudo é definido como exploratório, e foi construído a partir do permeio entre fontes primárias e secundárias, sendo estas o próprio objeto de estudo: a infância em contato com a dança.

Teve-se o intuito de produzir uma pesquisa qualitativa que, segundo Denzin e Lincoln (2006), envolve uma abordagem interpretativa do mundo, o que significa que seus pesquisadores estudam as coisas em seus cenários naturais, tentando entender os fenômenos em termos dos significados que as pessoas a eles conferem.

A pesquisa em questão se dispôs de entrevistas e questionários realizados com três professoras de uma mesma instituição de educação infantil privada, sendo estas: Participante A com formação em psicopedagogia trabalhando na instituição a quinze anos; Participante $B$ formada em pedagogia trabalhando na instituição a nove anos; Participante $C$ também formada em pedagogia, atuando na instituição a 5 anos. Os instrumentos de pesquisas foram materializados a partir de questões que envolvem a postura docente no meio educacional infantil, e indagações referente a como estas docentes compreendem a relação da dança como campo de ensino, visando descobrir as facilidades e dificuldades encontradas neste processo norteador do desenvolvimento educacional das crianças pequenas $\mathrm{e}$ entender de que modo a linguagem corporal destas crianças é levada em consideração quando compreendida de modo a se relacionar com a maneira em que aprendem coisas novas. As respostas foram obtidas de maneira individual, com o enfoque voltado para uma coleta de dados que não fossem influenciados pelas respostas umas das outras, de modo que as semelhanças que poderiam ocorrer dentre estas respostas, acontecessem de maneira ocasional. As entrevistas e os questionários aplicados possuíam cinco questões, onde o questionário disponibilizado para as professoras continha interrogações semiestruturadas, de modo a oportunizar flexibilidade para a realização de alterações, como complementar/retirar e argumentar tais questões.

As questões, de múltipla escolha respondidas pelas docentes foram:

1- Em sua concepção, o que significa dança?

Diferentes ritmos e modalidades ( )

Reprodução de movimentos ( ) 


\section{Expressão corporal ( )}

Linguagem corpórea ( )

Outros ( )

2- Nas suas práticas pedagógicas a dança se faz presente?

$\operatorname{Sim}($ ) Não ( )

3 - Você costuma conversar sobre consciência corporal com as crianças da sua turma?

$\operatorname{Sim}($ ) Não ( )

4 - Você costuma considerar a linguagem corporal das crianças como um dos meios de comunicação entre vocês?

$\operatorname{Sim}($ ) Não ( )

5 - Você considera as práticas educacionais dançantes oferecidas para as crianças na instituição em que você trabalha como sendo importantes?

Sim ( ) Não ( )

6 - Na sua opinião, existem contribuições que a prática da dança pode oferecer para o desenvolvimento das crianças?

$\operatorname{Sim}($ ) Não ( )

Se compreende que as docentes participantes desta pesquisa não são profissionais da área da Dança, especificamente, mas que sua forma de compreender a importância da Dança no cotidiano escolar influencia o modo como as crianças se relacionam com a linguagem. Entendemos que um olhar subjetivo sobre as respostas nos oportunizaria compreender a relação entre ensino e formação sensivel.

Buscou-se traduzir resultados em conceitos e ideias, visando conectá-los com as pesquisas bibliográficas utilizadas, tendo a valorização do processo como enfoque de toda a pesquisa, pretendendo contribuir de alguma maneira com aqueles que se familiarizam com o tema dança e infância e com a educação num contexto geral.

\section{DIFERENTES FORMAS DE LINGUAGEM: EXPRESSIVAS E COMUNICATIVAS}

A linguagem em qualquer uma de suas modalidades é fator essencial nas relações interpessoais e grupais, é por meio da linguagem que comunicamos nossas ideias e pensamentos. Entretanto, quando falamos em linguagem, nosso primeiro instinto nos leva a pensar na verbalização. Quando você possui 
uma ideia em pensamento, e deseja comunicar esta ideia, certamente você a explica por meio da linguagem verbal. Esta verbalização, muitas vezes, se concretiza por meio de seu corpo, que vem a ser a linguagem corporal.

Em todos os momentos, do nosso dia a dia, utilizamos a comunicação não verbal para nos comunicar. Consciente ou inconscientemente este meio de comunicação que possuímos e que por muitas vezes não exploramos, diz muito sobre o outro e sobre nós mesmos. Isto é linguagem corporal, o compartilhamento mesmo que indireto de nossos gestos, nossas expressões faciais e, até mesmo nossa postura, comunicam. Em um primeiro momento pode parecer difícil compreender, como uma pessoa pode se comunicar sem usar a fala. Pensemos na seguinte situação, quando estamos reunidos em um grupo de pessoas, e uma dessas pessoas comunica corporalmente o sinal de silencio, certamente todos deste grupo a entenderão sem que ela precise dizer uma só palavra. 0 mesmo acontece no nosso dia em inúmeras situações, porém, quase sempre estamos desatentos a este tipo de comunicação, nos concentrando somente naquilo que é verbalizado.

A leitura da linguagem corporal revela informações de como 0 indivíduo interage frente aos estímulos oriundos do meio em que se encontra, considerando o fato de que os estímulos partem da situação vivenciada pelas pessoas que estão em interação, e que cada participante os interpreta de maneira única. No ambiente escolar, além das singularidades pessoais, há situações harmoniosas, conflituosas, de lazer, em que interesses pessoais podem gerar ansiedade, felicidade, descontentamento, receio, conforto, enfim, um intrincado conjunto de fatores difíceis de se identificar somente por meio da palavra. Em uma ação pedagógica, em que as crianças das mais diversas personalidades trocam informações, é possível identificar, através da linguagem corporal, quem verdadeiramente está entusiasmado com a atividade, ou aborrecido, contrariado, satisfeito ou triste.

Sabemos que a movimentação na vida de uma criança se faz presente desde os seus primeiros dias de vida, já que é por meio de seu corpo que ela estabelece relações com o mundo ao seu redor. $A$ linguagem corporal de uma criança grita, e nós precisamos com urgência aprender a ouvi-las e interpretálas. Antes da linguagem verbal, todas as emoções e sensações de uma criança são exteriorizadas por meio de seu corpo, temos como dever desenvolver nossa sensibilidade para tal tipo de comunicação, para que possamos tornar nossas relações ainda mais afetuosas. Na visão de Pierre Guiraud em sua obra: A linguagem do Corpo, ele escreve que: "imaginamos o mundo segundo o modelo de nosso corpo, e assim formamos um conjunto de conceitos e de palavras a partir das imagens corporais" (GIRAUD, 
1991, p. 7). O mesmo ocorre com as crianças que, absorvem os conceitos, símbolos, imagens, gestos e ações, e em algum momento conscientemente ou não ela demonstra 0 que aprenderam nas suas interações.

Desde o seu nascimento a criança recebe, através de suas percepções sensoriais, informações e interações com os grupos sociais, selecionando e absorvendo para sua vida, ações, gestos e códigos. Soares nos diz que, "a inscrição que se move e cada gesto aprendido e internalizado revela trechos da história da sociedade a que pertence" (2006, p. 109) portanto, quando podamos o movimento da criança com um, "sente-se", "olhe, o seu amigo está sentado e você não", podamos também sua forma de se expressar e de se comunicar, precisamos entender a gravidade disto.

Guiraud (1991) descreve o corpo humano como aquele que nos revela sobre a identidade e personalidade da pessoa, evidenciando a linguagem corporal em duas funções: a descritora e a ação de exprimir. Mas para haver a comunicação e a constituição de um contexto, ideias e propósitos, a linguagem corporal necessita da relação entre os participantes, o emissor e o receptor, no caso deste estudo é o professor e o aluno e suas interações no processo de ensino e aprendizagem na educação infantil. Não cabe ao docente dizer quando a criança deve ou não se movimentar, é como se estivéssemos limitando o quanto ela pode ou não se comunicar com o outro. $E$ esta relação entre participante e comunidade, não deve ser limitada por meio de um desejo de o que o professor compreende como ordem e disciplina, mas deve ser sim explorada a partir dos desejos e vontades das crianças, já que elas são nosso foco de aprendizagem.

\section{O CORPO INFANTIL EM MOVIMENTO: A LINGUAGEM DA CRIANÇA}

Observando a linguagem corporal como predicado da educação infantil, necessitamos encontrar meios de utilizá-la a nosso favor, de modo que possamos compreendê-la e usufruí-la em sua magnitude, já que o ato de movimentar é o principal modo de expressão na infância.

Segundo Friedmann (2012), por meio das atividades lúdicas, não somente se abre uma porta para o mundo social e para as culturas infantis, como se encontra uma rica possibilidade de incentivar seu desenvolvimento. 0 autor Friedmann (2012) ainda acrescenta, a educação deveria ter sua preocupação voltada em propiciar a todas as crianças um desenvolvimento integral e dinâmico. E a relevância da comunicação corporal diz muito sobre como nossas práticas pedagógicas chegam até as crianças. Penso que devemos buscar provocar reações corporais dentro de sala de aula, tão significantes 
para as crianças, quanto as que são reverberadas em seus momentos de lazer, evidenciando o fato de que as ações pedagógicas não devem se contrapor a momentos de ludicidade e ao ato do brincar, acreditando que 0 ato de se movimentar livremente não necessariamente precise ter um momento único e restrito para acontecer, mas este deve ser explorado em todos os momentos do cotidiano infantil.

Quando colocamos o movimento como enfoque da educação infantil, os estudos sobre a dança podem auxiliar a pedagogia a renovar-se definindo novos princípios para o ensino.

Uma outra Pedagogia [...] uma pedagogia da escuta, uma pedagogia das relações,
uma pedagogia da diferença [...] onde além das ciências em que a Pedagogia busca
suas bases epistemológicas, também a arte é seu fundamento, garantindo assim a
ausência de modelos rígidos preparatórios para a fase seguinte e, além de um
cognitivismo característico das pedagogias, também a construção de todas as dimensões
humanas e o convívio com a diferença, "sem nenhum caráter" (FARIA e RICHTER, 2009,
p 286).

A dança por subsequência, é compreendida como uma grande aliada no que diz respeito a preocupação com o desenvolvimento da criança, buscando valorar toda a evolução deste contexto aproveitando as novas oportunidades educacionais que a nós é oferecido. Considerada uma arte que oportuniza a diversão, a livre expressão e a integração social, podemos por meio do movimento construir unificações de pessoas que respeitam e exploram suas diferenças. Para Nanni (2008, p. 1), "a Dança em sua essência - como manifestação primitiva, era um mergulho no mundo mágico, onde os movimentos espontâneos surgiram da imaginação (...)". A dança nos oferece uma infinidade de oportunidades e campos a serem descobertos, por meio de nosso corpo, órgãos e membros que se integram com sensibilidade e consciência oportunizando sustentação a gestos e movimentos.

A prática passou a ser compreendida como campo de ensino e muito já foi problematizado e questionado sobre a dança levar para dentro da escola essa estrutura padronizada e mecanizada de aulas, justamente o que se tem comentado até agora, como necessitando de mudanças no ambiente de escolarização. Esta estrutura padronizada, onde 0 aluno recebe produtos prontos, decora, reproduz, e tem como objetivo um produto, é denominada na atualidade como sendo uma postura ultrapassada. Segundo Berge "Trata - se aqui de uma verdadeira reviravolta pedagógica: o professor não mais dá ordens a seus alunos para obter sequências que lhe são impostas do exterior, mas torna - se guia que os orienta para uma descoberta pessoal de suas faculdades". (BERGE, 1988)

Quando pensada no contexto da educação, a dança deve ser concebida como parte do currículo, seja este humano, afetivo, cognitivo ou social, compreendendo a linguagem corporal como uma das formas de representação do conhecimento. 
Segundo Ossona (1988, p. 18), "a dança é uma disciplina que se deve começar quando se é bem pequeno, sobretudo quando os dotes físicos não são excepcionais", as movimentações das crianças são diversificadas e criativas. E principalmente, elas estão abertas a descobertas e sentem a necessidade de sempre estar aprendendo.

O movimento corporal acontece na inter-relação da pessoa com o mundo, e a dança, busca através de estímulos, proporcionar momentos de criação, apreciação e de troca entre a criança com outros indivíduos, subsidiada pela "Abordagem Triangular" de Ana Mae Barbosa (2008). A dança mediada por meio da metodologia criativa aqui se apresenta como interessada em contribuir nos processos que acompanham o crescer da criança, trabalha a partir da construção de saberes e da valorização dos processos, procurando manter o aluno como foco da aprendizagem, sabendo respeitar suas escolhas e oportunizando espaços de fala.

Uma das grandes contribuições da dança para a educação do ser humano, segundo Marques (1999) é educar participantes que sejam capazes de criar pensando e ressignificando o mundo em forma de arte. Entendemos que a criança

[...] é um ser em constante mudança e se utiliza disto para buscar conhecimento de si e de tudo o que está a sua volta. Atividades lúdicas que propiciem uma reflexão acerca da importância do movimento para a educação Infantil é de fundamental importância nas primeiras fases de desenvolvimento, e compreendemos que o caráter lúdico e expressivo das manifestações do movimento da criança poderá ajudar o professor a organizar melhor sua prática, levando em conta as necessidades motoras de cada criança, levando-as a vivenciar experiências, que as ajudem a compreender o mundo que as cercam. (SILVA, 2016, p. 9)

SILVA (2016) compreende que a prática dançante dentro da instituição escolar por vezes ainda é vulnerável no que diz respeito a valoração de produtos finalizados, e a prática da dança quando conduzida desta maneira acaba que por ser inferiorizada diante do que ela mesma pode oferecer, se resumindo a uma prática de exercício apenas.

[...] entre um ano e meio ou até os seis ou sete anos, mais ou menos, a criança costuma liberar a imaginação, a criatividade e a se comunicar umas com as outras, com partes do corpo e com objetos. Com isso a linguagem e a representação mental começam a fazer parte da vida da criança com maior intensidade, ou seja, a criança começa a fazer e a compreender. (SILVA, 2016, p. 12)

Como já referido, a ação do mover-se se faz presente desde os primeiros sinais de vida de uma criança, e o acesso à diferentes tipos de comunicações, neste caso por meio dos movimentos, oportunizam contribuições ao desenvolvimento delas. A prática dançante quando conduzida de modo a ter como enfoque de sua pratica as necessidades das crianças, surge como um campo de experiência auxiliador no desenvolvimento dos pequenos (SILVA, 2016). 


\section{COMO A DANÇA É COMPREENDIDA A PARTIR DAS PROFESSORAS ENTREVISTADAS}

Como observado nos capítulos anteriores, sabe-se que o movimento está presente na vida de uma criança desde os seus primeiros minutos de vida. Desde o momento em que esta criança se encontra no ventre de sua mãe, ela se move e se descobre por meio dos movimentos. Desde um piscar de olhos a um mover mínimo dos dedos, o cérebro da criança manda estímulos para que os músculos possam se movimentar, e por meio disto a linguagem corporal passa a se comunicar com seu exterior. Portanto, toda ação humana envolve atividade corporal.

A dança no âmbito educacional infantil, se apresenta como um meio artístico que possibilita a expressão, a diversão e a integração social. Para Nanni (2008, p. 1), "a Dança - em sua essência - como manifestação primitiva, era um mergulho no mundo mágico, onde os movimentos espontâneos surgiram da imaginação...". A educação infantil possui uma característica muito especifica no que diz respeito a explorar, não existem barreiras para a exploração, tudo é novo, tudo é descoberta. Existem uma infinidade de possibilidades contidas neste primeiro contato da criança com a educação, e a dança, aqui se apresenta como campo de ensino, capaz de contribuir de maneira significante no desenvolvimento das crianças.

O coreógrafo, pesquisador e bailarino Rudolf Laban (1990) relata que, os movimentos do ser humano na dança, se expressam na riqueza de gestos que são reproduzidos no cotidiano. Neste sentido, a dança passa a ser compreendida não como uma limitação e decodificações especificas de movimentos, dos quais necessitam serem decorados e reproduzidos. Em sua essência, a dança não sobrevive de superficialidades, mas se distingue por suas subjetividades e distintas possibilidades.

Portanto, a dança pensada no contexto educacional infantil, é concebida como parte do conhecimento que a criança traz consigo, e a partir disto, destas singularidades e especificidades, que estímulos são oportunizados para que a criança vivencie experiências que envolvam a exploração, a criação, a descoberta e o reconhecimento, pois é por meio das relações entre corpo e movimento, que uma afinidade mais significante entre a criança e o seu próprio corpo surge.

LIMA e SARAIVA (2012), comentam que a experiência

[...] não é somente o acúmulo de anos vividos, de compromissos e problemas resolvidos [...] a experiência é mais do que isso, pois experimentar algo é viver em plenitude, seja em curto ou em longo espaço de tempo, visto que existem valores que não se prestam à experiência. [...] Por meio do bombardeio de informações diárias, somos levados a ter somente vivências que partem de algo externo a nós mesmos. Nossas experiências na vida moderna efetuam-se fora 
de nós mesmos, visto que nossas referências se baseiam, geralmente, sobre o que as pessoas dizem, pensam e determinam para nós. (LIMA E SARAIVA, 2012 p. 3)

É possivel assentir com esta afirmação, se analisadas as condições que contextuam o dia a dia da criança. Sabe-se que a função da escola é oportunizar momentos de vivenciar novas experiências, mas de fato, muitas vezes estas experiências estão atreladas a algo externo, no qual quem diz quem, como e por quanto tempo "experienciar" é o adulto. Dificilmente é disponibilizado a criança a autonomia de explorar a si mesmo enquanto fonte inesgotável de descoberta. A dança emerge de um mundo próprio, único e singular na região do imaginário, do encantamento, do êxtase e do prazer, Huizinga (1993).

Para que se pudesse discutir a relação entre a Dança e o espaço da Educação Infantil foi atribuído as docentes questões específicas da relação entre aprendizado do corpo e 0 ensino, as questões foram respondidas conforme segue:

llustração 01 - Respostas ao Questionário

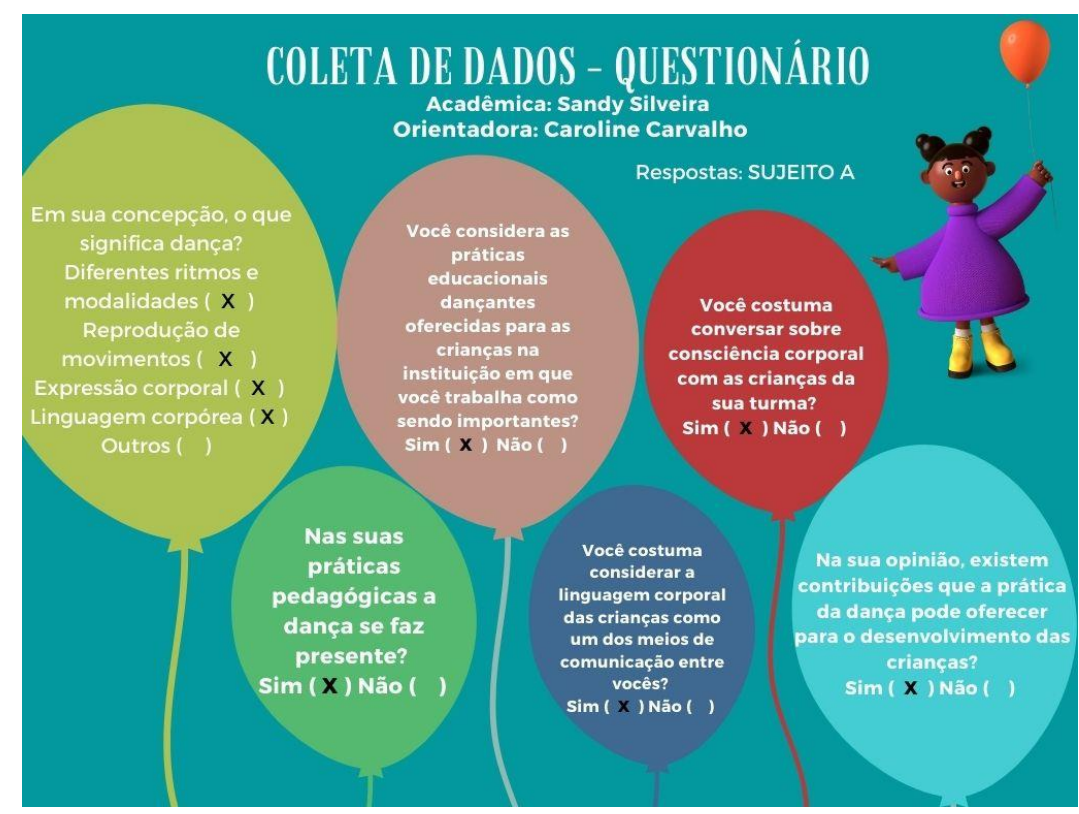

FONTE: acervo da autora

As participantes que responderam a este questionário, receberam a indagação de o que para eles, "significa dança?". A participante A assinalou as seguintes opções: Diferentes ritmos e modalidades - Reprodução de movimentos - Expressão corporal - Linguagem corpórea. Já as participantes B e C, descartaram a questão que mencionava a reprodução de movimentos. 
As metodologias utilizadas nas práticas pedagógicas dançantes abordam movimentos repetitivos sim. Por mais contraditório que possa parecer, a repetição é capaz de abordar aspectos específicos do desenvolvimento infantil. Sem sombra de dúvidas, as práticas que abordam a reprodução de movimentos, possuem objetivos específicos como almejados. De maneira alguma, a reprodução aqui poderá se apresentar como um meio tecnicista. Isto exige um grande esforço profissional, já que esta prática de repetição não pode surgir de maneira vaga, mas sim, de modo muito bem contextualizado.

Nesta ocasião será exemplificado a partir de observações participativas a prática dançante para o berçário I, esta turma em específico abrange crianças de 0 á 1 ano. Nesta situação, fala-se de bebês que ainda não sustentam o próprio corpo sem auxílio de um adulto, ao mesmo tempo em que outros vivenciam os primeiros passos. Nesta fase em especial, a repetição de movimentos surge como uma ferramenta capaz de auxiliar no desenvolvimento destas crianças. Quando a professora põe estímulos musicais que fazem associações a se colocar em uma posição onde suas mãos escondam o seu rosto por exemplo, por instantes as crianças podem achar engraço, diferente e até estranho. Mas na aula seguinte, quando a professora repete esta mesma movimentação de esconder o rosto com suas mãos, de maneira gradativa, as crianças já serão capazes de associar as próprias mãos e buscar esconder o próprio rosto ou o rosto do outro, buscando imitar esta movimentação. Este é um momento de descoberta. Com uma situação extremamente exemplificada como esta, já se pode compreender a importância do ato da repetição de movimentos para as crianças. Este simples exercício, faz com que os membros e músculos das crianças comportem estes novos movimentos em suas memórias corporais. $\mathrm{O}$ ato de repetir é defendido pelo fato de visar objetivos específicos como, reconhecer partes do corpo, desenvolver habilidades motoras, trabalhar a atenção e realizar a imitação. Portanto, a ação de reproduzir movimentos, quando pensada de modo a atender as necessidades das crianças, pode ser oferecida pela prática dançante como um meio contribuinte do desenvolvimento infantil.

As participantes também foram questionadas sobre: "Em suas práticas pedagógicas a dança se faz presente?". As participantes A, B e C assinalaram a alternativa afirmativa, confirmando a utilização da dança em suas aulas.

Esta resposta revela muito sobre como estas participantes conduzem suas práticas pedagógicas. Oportunizar a familiarização da criança com a música e com os movimentos, significa oferecer acesso a arte, a cultura, a oportunizar também a experimentação, exploração e compreensão de significados culturais presentes no seu meio e, consequentemente, elaborar e/ou ressignificar o seu 
pensamento. Sendo isto por meio da observação dos movimentos de outra criança, ou do grande grupo e até mesmo da professora. Essa aproximação com a liberdade de expressão, de poder dialogar com 0 próprio corpo e interagir com o outro, significa soltar-se das amarras impostas no século XIX, onde ensinar significava disciplinar e generalizar, tornando todos similares, sem abertura para singularidades. E aqui se prioriza o diferente, o ser único, o ser criativo e individual.

Le Boulch (1981) argumenta que a educação psicomotora deve ser considerada uma educação essencial no ramo infantil. $O$ autor complementa que,

(...) ela condiciona todos os aprendizados pré-escolares e escolares; leva a criança a tomar consciência de seu corpo, da lateralidade, a situar-se no espaço, a dominar o tempo, a adquirir habilmente a coordenação de seus gestos e movimentos. A educação psicomotora deve ser praticada desde a mais tenra idade; conduzida com perseverança, permite prevenir inadaptações, difíceis de corrigir quando estruturadas. (apud Almeida 2006, Le Boulch, 1981, p. 27).

É praticamente inimaginável, pensar em desenvolvimento infantil e não o atrelar ao movimento. A vida é movimento, é impossível se desassociar disto.

Como indagação seguinte, as participantes receberam a seguinte questão, "Você costuma conversar sobre consciência corporal com as crianças da sua turma?". Todas as participantes responderam afirmativamente, o que resulta em uma sensação de conforto obviamente. A consciência corporal não é uma capacidade inata, mas sim desenvolvida nas relações entre indivíduo e ambiente. Para Melo (1997), o termo consciência corporal engloba todas as relações do participante com o mundo, unindo a imagem corporal e o esquema corporal, que segundo ele, ocorrem simultaneamente no desenvolvimento da criança.

É nos primeiros anos de vida de uma criança, conhece seu próprio corpo, e o professor por sua vez tem como missão oportunizar estímulos que ofereçam a identificação dos membros deste corpo, a compreensão sobre quais movimentos esse corpo é capaz de realizar, a identificação do tamanho desse corpo, a percepção de seus limites, e a exploração de possibilidades. Segundo Rosa \& Nisio (2002), o estímulo da consciência corporal torna o corpo da criança como um ponto de referência básico para a aprendizagem de todos os conceitos indispensáveis à alfabetização, como noções de lateralidade e espacialidade, permitindo assim o equilibrio corporal e o domínio de seus impulsos motores.

Mattos \& Neira (1999), indicam práticas pedagógicas que propiciem à criança o conhecimento da nomenclatura, identificação, localização e conhecimento das diferentes partes do corpo em si e no 
outro; exploração das diferentes posições do corpo, como de pé, deitada, decúbito dorsal, ventral ou lateral, sentada, invertida, inclinada etc.

A consciência corporal pode ser desenvolvida nos mínimos detalhes, desde desenhos em partes especificas do corpo como pequenos símbolos em membros isolados (mão/pé/braço/perna). Como oportunizar que a criança entre dentro de caixas, para perceber que tamanho o seu corpo possui. Estes simples estímulos fazem com que a atenção das crianças se volte para si mesmos, de modo com que ela passe a identificar aquela parte do corpo e identificá-la como pertencente a si, aprendendo sua nomenclatura, sua função motora, e suas capacidades físicas. É com passos de formiga que se constrói um formigueiro. Por meio de pequenos estímulos o docente é capaz de fornecer um desenvolvimento sadio, lúdico e significativo na vida das crianças. E a consciência corporal é uma ferramenta essencial.

A questão seguinte dizia, "Você costuma considerar a linguagem corporal das crianças como um dos meios de comunicação entre vocês?" os três participantes responderam positivamente. Esta questão diz muito sobre como as participantes se colocam como ouvintes para as crianças. Graciosamente todas afirmam prestar atenção nestes detalhes, o que significa que a comunicação entre estes vai para além da oralidade.

Conseguir compreender quando a criança se sente desconfortável, irritada, cansada, ou entusiasmada e animada, todos estes fatores estão diretamente ligados a maneira com que 0 ensino chega nestas crianças. Forçar uma aprendizagem, como já visto anteriormente, é uma postura ultrapassada, das quais os professores necessitam lutar para não a fazer, de modo que oportunizando esta comunicação sensível, e empática, fornece para a criança um ensino de qualidade onde suas vontades são levadas em consideração. Trata-se de mais um dos deveres dos quais a professora precisa se atentar, desenvolver maior sensibilidade para o que diz respeito a interpretação da comunicação não verbal com suas crianças.

Como última indagação, as participantes responderam à pergunta: "Na sua opinião, existem contribuições que a prática da dança pode oferecer para o desenvolvimento das crianças?", todas as participantes, A, B e C responderam de maneira afirmativa. Acreditar na potencialidade da dança, é acreditar que a vida está diretamente atrelada ao movimento. É crer que o ser humano foi criado para se movimentar. Todas as partes que constituem um corpo humano saudável, são perfeitamente planejadas para se desenvolverem por meio do movimento. 0 cérebro encontra-se em perfeita harmonia com os 
neurônios que estão sempre atentos às informações que são concebidas de maneira externa. 0 interno do corpo humano pode ser comparado a um universo, do qual se transmuta e evoluí a cada instante.

Acreditar na eficiência da prática dançante é conscientizar-se sobre a importância de manter um diálogo que se dispõe da afinidade e sensibilidade com o próprio corpo e com o corpo do outro. O corpo humano é composto por uma infinidade de curiosidades e possibilidades, das quais só podem ser exploradas por meio de uma aproximação e disponibilização de uma escuta. E esta escuta se desenvolve por meio de métodos dos quais a consciência se aproxima da corporeidade, de modo que ambas se tornam um só, e por meio deste elo, a relação entre o indivíduo e suas concepções sobre seu corpo, tornam-se mais intimas e particulares, pois se dispões de experiencias e vivencias que são extremamente individuais. Dançar é expressar-se, é criar, recriar, experimentar, explorar, descobrir e evoluir. Dançar é se ouvir!

MARQUES (2003), afirma que a prática dançante, permite uma leitura e uma releitura diferenciada de nós mesmo e do outro. Através do corpo que se move, que dança, é possível estabelecer relações com a sonoridade, com o campo visual e com a oralidade que cercam o cotidiano humano. Deste modo, a dança cumpre um papel importante na educação do indivíduo enquanto cidadão crítico e transformador.

É possível assentir com o fato de que o fazer pedagógico da dança se mostra eficaz para o desenvolvimento das crianças. Portanto, por meio desta prática que se apresenta como ferramenta contribuinte, é possível atender necessidades especificas e singulares das crianças pequenas. Acreditando que a mudança que se visa no âmbito educacional depende também do esforço do docente em encontrar métodos que facilitem este processo.

\section{CONSIDERAÇÕES FINAIS}

Através das análises realizadas por meio das captações de dados aqui apresentadas, foi permitido a efetuação de em diálogo com as bibliografias utilizadas, de maneira a contextualizar e fundamentar as questões que surgiram, fazendo um diálogo entre, pesquisa, teoria e prática cotidiana. Encontrando métodos capazes de edificar e auxiliar a prática docente infantil, tendo como foco o maior e mais sadio desenvolvimento das crianças. Foi oportunizado analisar e repensar metodologias docentes, de maneira a compartilhar fatos que validam que o pensamento que permeou gerações das quais eram ensinadas por meio de uma visão estereotipada, na qual a criança era apenas mais uma 
pertencente a um grande grupo que era abordado através de uma padronização, como sendo um modo de pensar ultrapassado.

A partir dos diálogos, costuras e relações oferecidos por esta pesquisa, acredita-se ter se alcançado as questões objetivadas em seu início. Os referenciais teóricos quando em contato direto com as experiências práticas oportunizam reflexões acerca da postura docente e as práticas pedagógicas do outro, e a própria, de modo a disponibilizar a oportunidade de crescimentos e ressignificações.

O docente na maior parte das vezes, se encontra em uma posição de fala, mas, poucas vezes tem a oportunidade de compartilhar sobre seus desafios enfrentados nessa posição. Portanto, buscouse oportunizar momentos de uma escuta afetiva para com eles, na qual procurou-se contribuir na resolução de problemas específicos enfrentados por estes. Contudo, espera-se que esta investigação possa contribuir de alguma maneira com aqueles que se preocupam com um fazer educacional empático, afetivo e humano.

As investigações realizadas contribuíram inclusive para a descoberta de métodos de ensino que abordam a arte de maneira direta com o processo da construção de conhecimentos, de maneira contextualizada, demonstrando eficiência em seu desenvolvimento de execução.

\section{REFERÊNCIAS}

BARBOSA, Ana Mae (Org.). Ensino da arte: memória e história. São Paulo: Perspectiva, 2008.

BERGE, Yvonne. Viver o seu corpo: por uma pedagogia do movimento. $4^{\mathrm{a}}$ ed. São Paulo: Martins Fontes, 1988

DENZIN, Norman K.; LINCOLN, Yvonna. A disciplina e a prática da pesquisa qualitativa. In: DENZIN, Norman K.; LINCOLN, Yvonna (orgs). Planejamento da pesquisa qualitativa: teorias e abordagens. 2 ed. Porto Alegre: ARTMED, 2006.

FRIEDMANN. A importância do brincar. Jornal diário na escola: Santo André/SP, 2003.

GIL, Antonio Carlos. Como elaborar projetos de pesquisa. 4. ed. São Paulo: Atlas, 2002. 176 p. Disponível em: https://ava3.furb.br/pluginfile.php/545995/mod_resource/content/3/Como_elaborar_projetos_de_pesqui sa_-_Antonio_Carlos_Gil.pdf. Acesso em: 5 nov. 2020.

GUIRARD, Pierre. A linguagem do corpo. Trad. Lólio Lourenço de Oliveira. São Paulo: Ática, 1991. HUIZINGA, J. Homo Ludens: o jogo como elemento da cultura. São Paulo: Perspectiva, 1993. LABAN, Rudolf von. Dança Educativa Moderna. SP: Ícone, 1990. 
LE BOULCH, Jean. 0 desenvolvimento psicomotor do nascimento até 6 anos. Porto. Alegre: Artes Médicas, 1982

LIMA, Elaine; SARAIVA, Maria. Que dança faz dançar a criança?: Ampliando as experiências na infância por meio da dança. Currículo e infância., [s. l.], 13 fev. 2012.

NANNI, Dionisia. Dança educação: pré escola à universidade. $5^{\mathrm{a}}$ ed. Rio de Janeiro: Sprint, 2008.

MARQUES, Carlos A.; MARQUES, Luciana P. Do universal ao múltiplo: os caminhos da inclusão. In: LISITA, V.; SOUSA, L. (Orgs.). Práticas educacionais, práticas escolares e alternativas de inclusão escolar. Rio de Janeiro: DPA, 2003.

MATTOS, Mauro Gomes de e NEIRA, Marcos Garcia. 0 papel do movimento na Educação Infantil. IN NICOLAU, Marieta Lúcia Machado e DIAS, Marina Célia Moraes (org.) Oficinas de Sonho e Realidade na Formação do Educador da Infância. Campinas, SP: Papirus, 2003.

MELO,R.Z. Educação Física na escola: conteúdos adequados ao 20 grau. Rio Claro: UNESP, Monografia de Graduação, Instituto de Biociências, Departamento de ducação Física, 1995.

OSSONA, P. A educação pela dança. Tradução de Norberto Abreu e Silva Neto. São Paulo: Summus, 1988.

RICHTER, Sandra Regina S. Apontamentos pedagógicos sobre o papel da arte na educação da pequena infância: como a pedagogia da educação infantil encontra-se com a arte? In: Small Size Paper. (Org.). Experiencing art in early years-learning and development processes and artistic language. Bologna: Edizioni Pendragon, 2009. p. 103-125.

ROSA, Adriana; NISIO, Joseane di. Atividades lúdicas - sua importância na alfabetização. Curitiba: Juruá, 1998.

SILVA, João Da Mata Alves Da. O lúdico como metodologia para o ensino de crianças com deficiência intelectual. $2012 . \quad$ Disponível em: http://repositorio.roca.utfpr.edu.br/jspui/bitstream/1/4736/1/MD_EDUMTE_II_2012_33.pdf acesso em 26 março 2017.

SOARES, C.L.S. et al. Metodologia do ensino de educação física. São Paulo: Cortez, 1992. 